\title{
Research on the Construction Priority Model of Bus Lanes
}

\author{
Lijing Song ${ }^{1,2}$, Xiaoduan Sun1, Yulong He ${ }^{1}$ \\ ${ }^{1}$ Beijing Key Laboratory of Traffic Engineering, Beijing University of Technology, Beijing, China \\ ${ }^{2}$ Beijing Transport Institute, Beijing, China \\ Email: 691308560@qq.com
}

How to cite this paper: Song, L.J., Sun, X.D. and He, Y.L. (2019) Research on the Construction Priority Model of Bus Lanes. Open Journal of Applied Sciences, 9, 260269.

https://doi.org/10.4236/ojapps.2019.94022

Received: March 18, 2019

Accepted: April 23, 2019

Published: April 26, 2019

Copyright () 2019 by author(s) and Scientific Research Publishing Inc. This work is licensed under the Creative Commons Attribution International License (CC BY 4.0).

http://creativecommons.org/licenses/by/4.0/

(c) (i) Open Access

\begin{abstract}
Priority of public transport is one of the important means to enhance the attraction of ground public transportation, and also an important content in the construction of a public transport city. In recent years, Beijing has witnessed large-scale construction of Bus Lane. Based on the current situation that the construction of Bus Lane lacks scientific decision-making methods, this study establishes the time sequence evaluation indicator system for the construction of Bus Lane by analyzing the influencing factors, builds a ranking model of the importance degree of the construction of Bus Lane, and conducts case verification.
\end{abstract}

\section{Keywords}

Bus Lane, Time Sequence of Construction Model, Importance Degree, Indicator System

\section{Introduction}

Priority of public transport is one of the important means to enhance the attraction of ground public transportation, and also an important content in the construction of a public transport city. After more than 20 years of development, the network for Bus Lane has been basically formed since the first Bus Lane was arranged on Changan Avenue in 1997. The network has covered the main trunk roads of the central city and the sub-center, and initially formed a "one ring, three horizontal and eight radial" rapid commuting system of public transport. The allocation for Bus Lane plays an important role in improving the level and attractiveness of ground public transportation services, enhancing citizens' travel experience, making efficient use of road resources, and realizing energy conservation and emission reduction, as well as guiding urban development, etc. The 
average operating speed of Bus Lane is 33\% higher than that of non-dedicated lanes. After the opening of the Bus Lane and the fast direct line, the commuting time of Beijing residents, especially the new city residents, to the main employment attractions in the central city has been significantly reduced, effectively improving the travel experience of citizens. Buses on Beijing-Tongzhou fast road and Beijing-Kaifeng Expressway almost have the same speed as that of cars. The passenger flow carried by dedicated lanes is 2.5 times that by other lanes, which plays an important role in saving road resources. Residential and office facilities along the Bus Lane account for 73\% of Beijing's total, and the 500 meters along the Bus Lane can cover $62 \%$ of Beijing's resident population.

Although remarkable achievements have been made in the construction of Bus Lane in Beijing, there are still some problems in setting dedicated lanes, such as mismatch between the supply and demand and discontinuity of intersections. On top of that, Beijing has seen large construction of Bus Lane in recent years, with an average growth of 40 kilometers per year. By the end of 2018, the length of Bus Lane had reached 952 kilometers. Against the background of non-capital function transfer, construction of a sub-center and supply-side structural reform in public transport, Beijing is in urgent need to form a reserve project of Bus Lane allocation and determine the annual plan for Bus Lane allocation according to the actual travel demands for bus, the optimization and adjustment of public transit network and the construction of networks for roads and rails in the future, which require a scientific method system and reasonable process to support decision-making. Beijing, however, still lacks such a method system. For this reason, this study mainly analyzes the factors influencing construction of Bus Lane, to establish an indicator system and build a ranking model of importance degree, thus providing a reasonable process system to guide the construction of Bus Lane.

\section{Theory for Time Sequence of Construction of Bus Lane}

The time sequence of construction of Bus Lane is used to analyze the main factors influencing the construction of Bus Lane to establish an indicator system for evaluation of Bus Lane and form Bus Lane planning methods and processes by building a ranking model of importance degree, thus determining project reserves and construction plans for Bus Lane in a reasonable manner. In this way, the following targets will be achieved: improvement of operational reliability of ground public transportation, enhancement of ground public transportation service, attraction of car users to choose public transport, optimization of the structure of travel, alleviation of traffic jam in Beijing, improvement of air quality and provision of benefits for people. Meanwhile, through the planning of Bus Lane, the urban transportation development strategy with bus as a priority is implemented to promote the construction of a public transport city and to strengthen the coordination and integrated development of public transportation with the city. 
Through the existing studies at home and abroad, there are some studies on the importance ranking of transportation infrastructure. For instance, Qu Dayi et al. applied the systemic analytic hierarchy process (AHP) to the ranking of highway network planning and construction projects, with a consideration of such influencing factors as economy, technology and environment, to obtain the maximum construction benefits on the whole. Zhou Wei et al. used the analytic hierarchy process to determine the weight to calculate the indicator of the importance degree of transportation nodes. According to the demand of the road transport station at the transportation node, the indicator of importance degree of the node is revised as the demand indicator of the road transport station at the node. Through the demand indicator of the road transport station, the construction sequence of the road transport station is obtained by the circular comparison method. Luo Jian et al. made a comparative study on the planning scheme for road networks by employing the grey relational analysis method and the variable weighted sorting method. However, at present, no scholar has put forward the theoretical study and method system on the time sequence of construction of Bus Lane, and there is a lack of factor analysis and indicator system that affect the time sequence of construction of Bus Lane. Based on the above analysis, this paper solves the problem of the time sequence of construction of Bus Lane by referring to the theory of importance degree ranking of transportation infrastructure, which mainly involves key and difficult problems in 5 aspects: determination of the factors influencing the priority in construction of Bus Lane, establishment of an indicator system, determination of the indicator weight, and building of the model of priority ranking in construction of Bus Lane, and proposal of suggestions for construction of Bus Lane according to actual conditions of engineering construction and fund demand. The specific technical route is shown in Figure 1 Maintaining the Integrity of the Specifications.

\section{Building of Model for Ranking of Importance Degree}

\subsection{The Establishment of Indicator System for Time Sequence of Construction of Bus Lane}

The most basic function of Bus Lane is to improve the speed and attractiveness of ground public transportation. Meanwhile, the service efficiency of Bus Lane is higher than that of other lanes, so they can alleviate traffic congestion. Aside from that, the Bus Lane allocated can improve the public transport convenience of main passenger attraction points, and the rapid commuting corridors built based on the dedicated lanes can easily attract more residents to settle around, so the dedicated lanes can also guide urban development and support the construction of key functional areas. Based on the consideration of these aspects and the existing local standard (Setting of Bus Lane) of Bus Lane [1] [2], as well as the requirements for Bus Lane in the assessment index system of bus cities, 5 different factors affecting the time sequence of construction of Bus Lane are 


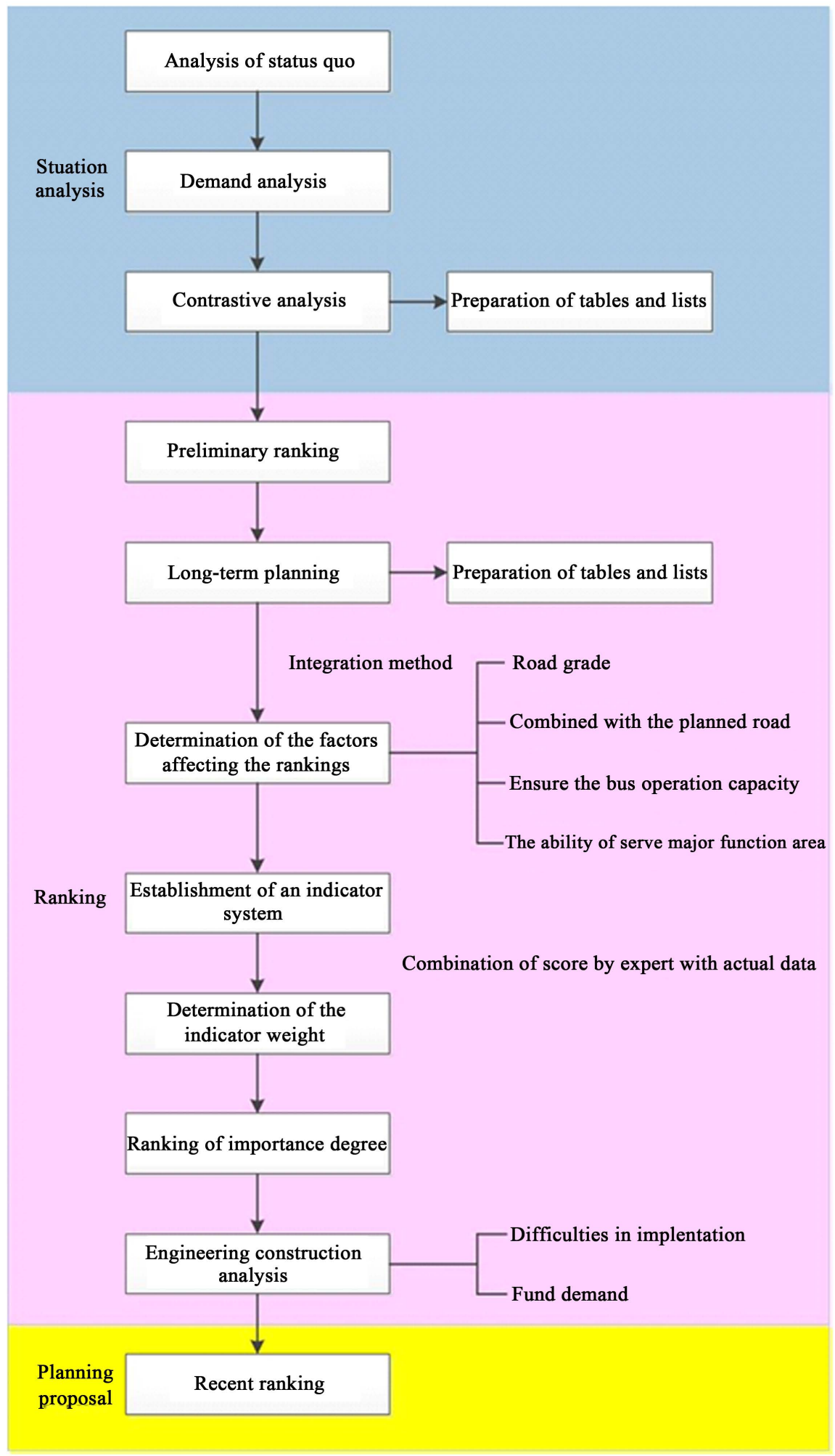

Figure 1. Technical route for study on time sequence of construction of bus lane.

determined, including: guarantee of bus operation, alleviation of congestion, the relationship with other planning facilities, improvement of bus convenience and travel in key service areas [3] [4]. 
On the basis of determining the influencing factors [5], the indicators related to each influencing factor are taken into account to build a system of 5 major indicators and 12 minor indicators, as shown in Figure 2.

\subsection{Determination of Indicator Weight}

The indicator weight is determined according to the expert investigation method and entropy evaluation method. For the expert investigation method, experts are mainly selected from government departments, scientific research institutions and colleges and universities. Based on the questionnaire survey, experts are asked to fill in the questionnaire and score each indicator according to their understanding of the importance of each indicator. To avoid subjectivity of the expert questionnaire method, the entropy evaluation method is used to determine the weight of the indicator layer, and the target layer (three different types of experts from government departments, scientific research institutions and colleges and universities) is given different weights. The final weight of each indicator is determined by comprehensive statistics of the weight of target layer and that of the indicator layer.

Main steps for the entropy evaluation method are as follows:

Step 1: Normalization processing of a standardized decision matrix:

$$
p_{i j}^{t}=\frac{y_{i j}^{t}}{\sum_{i=1}^{m} y_{i j}^{t}}, \quad j=1,2, \cdots, n ; t=1,2, \cdots, k
$$
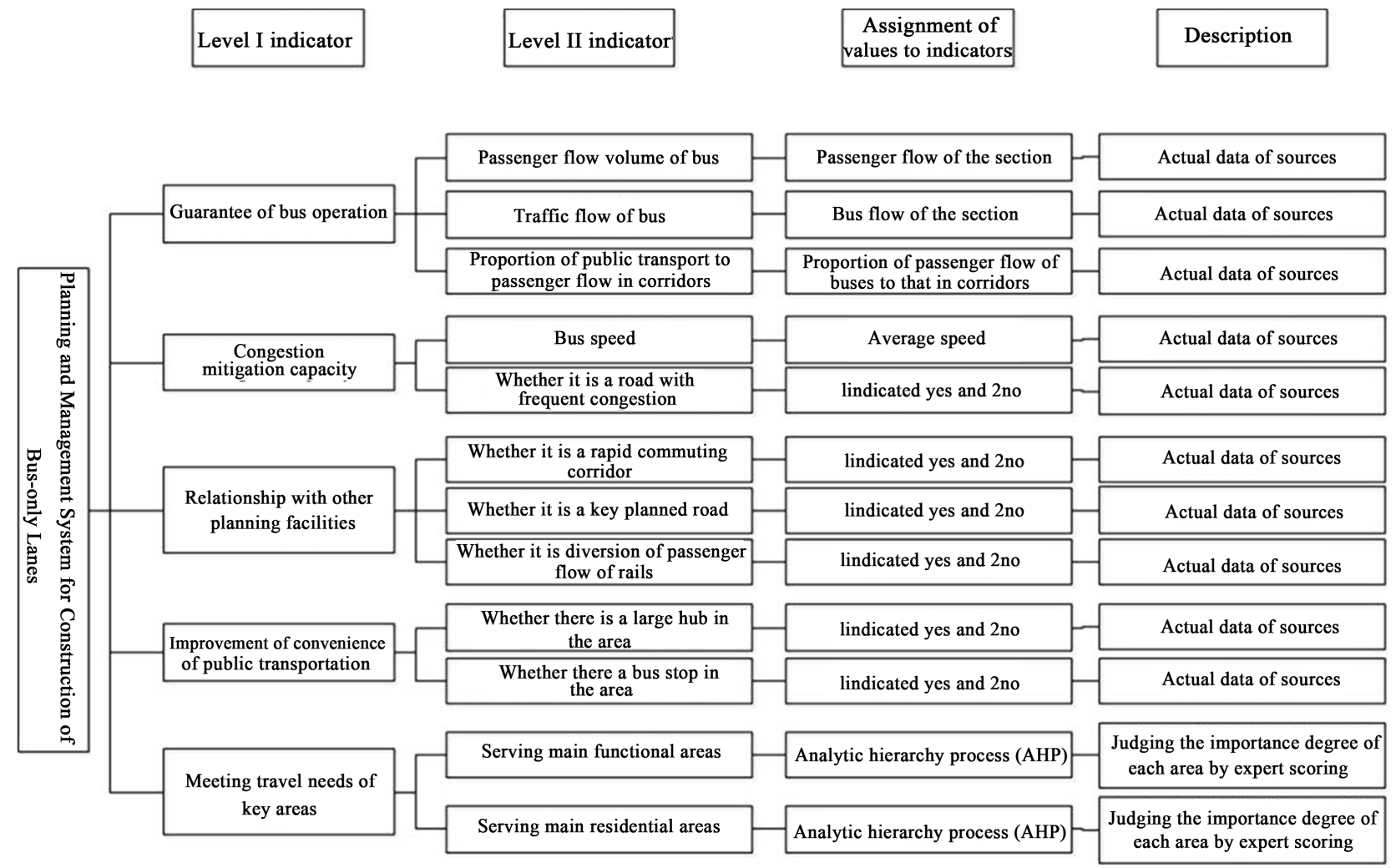

Figure 2. Indicator system. 
Step 2: Calculation of the entropy of the jth indicator:

$$
E_{j}^{t}=-k \sum_{i=1}^{m} p_{i j}^{t} \ln p_{i j}^{t}, \quad j=1,2, \cdots, n ; t=1,2, \cdots, k
$$

Step 3: Calculation of the diversity factor of the jth indicator:

$$
G_{j}^{t}=1-E_{j}^{t}
$$

Step 4: Determination of indicator weight:

$$
w_{j}^{t}=\frac{G_{j}^{t}}{\sum_{j=1}^{n} G_{j}^{t}}, \quad j=1,2, \cdots, n ; t=1,2, \cdots, k
$$

$W^{t}=\left\{w_{1}^{t}, w_{2}^{t}, \cdots, w_{n}^{t}\right\}$ indicates the normalized weight vector of an indicator in stage $t(t=1,2, \cdots, k)$.

\subsection{The Ideal Solution Method-Grey Relational Degree Theory Builds the Model of Comprehensive Importance Degree of the Project}

1) The fundamental principles of the theory

The theory was proposed by Hwang and Yoon in 1981. It is a kind of effective multi-attribute decision-making method. The basic idea of this method is to use the idea of ideal solution and negative ideal solution in multi-objective decision problem, to construct the ideal solution and negative ideal solution of the problem, and to evaluate each object by using two benchmarks close to the ideal solution and away from the negative ideal solution. It is the basis for judgment.

2) The ranking steps

The calculation of comprehensive importance degree of the project is a core part of the ranking model. The steps of the model can be summarized as follows:

Step 1: Select an evaluation indicator; select an indicator according to the evaluation indicator system of the construction plan.

Step 2: Determine the indicator value and conduct standardized treatment to from a decision matrix.

Step 3: Determine the indicator weight according to the entropy evaluation method.

Step4: Conduct standardized treatment of the decision matrix to determine an ideal scheme and a negative ideal scheme. Assuming that

$p_{j}^{t \wedge}=\max _{1 \leq i \leq m}\left\{p_{i j}^{t} \mid(j=1,2, \cdots, n ; t=1,2, \cdots, k)\right\}$, then $P_{\wedge}^{t}=\left\{p_{1}^{t^{\wedge}}, p_{2}^{t^{\wedge}}, \cdots, p_{n}^{t^{\wedge}}\right\}$ is

taken as the project of dedicated lanes with the highest comprehensive importance degree at $t(t=1,2, \cdots, k)$ under ideal conditions. Assuming that $p_{j}^{t \vee}=\min _{1 \leq i \leq m}\left\{p_{i j}^{t} \mid(j=1,2, \cdots, n ; t=1,2, \cdots, k)\right\}$, then $P_{\vee}^{t}=\left\{p_{1}^{t \vee}, p_{2}^{t \vee}, \cdots, p_{n}^{t \vee}\right\}$ is taken as the project of dedicated lanes with the lowest comprehensive importance degree at $t(t=1,2, \cdots, k)$ under ideal conditions.

Step 5: Use the grey correlation analysis method to respectively build grey relational coefficient matrixes of an alternative scheme and ideal and negative ideal scheme, and conduct weighting to determine the grey relational degree.

Assuming that $\xi_{i j}^{t \wedge}$ and $\xi_{i j}^{t \vee}$ indicate the correlation coefficient of $P_{i} \&$ 
$P_{\wedge}^{t}$ and $P_{\vee}^{t}$ at $I_{j}^{t}$, and the weighted grey relational degree of $P_{i} \& P_{\wedge}^{t}$ and $P_{\vee}^{t}$ is $\gamma_{i}^{t \wedge}$ and $\gamma_{i}^{t \vee}$ respectively, then:

$$
\begin{gathered}
\gamma_{j}^{t \wedge}=\sum_{j=1}^{n} w_{j}^{t} \xi_{i j}^{t \wedge}, i=1,2, \cdots, m ; t=1,2, \cdots, k \\
\gamma_{j}^{t \vee}=\sum_{j=1}^{n} w_{j}^{t} \xi_{i j}^{t \vee}, i=1,2, \cdots, m ; t=1,2, \cdots, k \\
I_{i}^{t}=\frac{\gamma_{i}^{t \wedge}}{\gamma_{i}^{t \wedge}+\gamma_{i}^{t \vee}}, i=1,2, \cdots, m ; t=1,2, \cdots, k
\end{gathered}
$$

$I_{i}^{t}$ indicates the comprehensive importance degree of a dedicated lane project at $t(t=1,2, \cdots, k)$.

Step 6: Rank the schemes according to grey relative similarity degree. According to the value of the $I_{i}$, the decision maker ranks all construction projects of Bus Lane to determine construction sequence of each project.

\section{Case Analysis}

Take the allocation project of Bus Lane in 2017 as an example: According to the actual data acquisition, 8 indicators are selected from the indicator system established in Section 3.1 to build an indicator table (specific indicators are shown in Table 1). Based on the IC card data of buses in May 2017, data such as passenger flow of a section, bus flow and speed are obtained to determine whether the road is a commuting corridor and located in a key functional area according to the road layout and relevant planning, and to assign values to each Bus Lane, so as to form an indicator table of Bus Lane, as shown in Table 1. Each indicator is standardized according to the dimensionless treatment method proposed in Section 3. The weight of each indicator is determined according to the expert investigation method (different experts are given different weights: 0.6 for government departments, 0.2 for colleges and universities, and 0.3 for scientific research institutions) and the entropy evaluation method, and the weight of each

\begin{tabular}{|c|c|c|c|c|c|c|c|c|c|}
\hline $\mathrm{S} / \mathrm{N}$ & Road name & $\begin{array}{c}\text { Passenger flow } \\
\text { of the section } \\
\text { (person-time/hour) }\end{array}$ & $\begin{array}{l}\text { Traffic flow } \\
\text { (number of } \\
\text { buses/hour) }\end{array}$ & $\begin{array}{l}\text { Speed } \\
(\mathrm{km} / \mathrm{h})\end{array}$ & $\begin{array}{l}\text { Whether } \\
\text { traffic jam } \\
\text { occurs } \\
\text { frequently }\end{array}$ & $\begin{array}{c}\text { Rapid } \\
\text { commuting } \\
\text { or not }\end{array}$ & $\begin{array}{l}\text { Whether it is } \\
\text { a road with } \\
\text { key planning }\end{array}$ & $\begin{array}{l}\text { Serving } \\
\text { the } \\
\text { functional } \\
\text { area }\end{array}$ & $\begin{array}{l}\text { Serving } \\
\text { the } \\
\text { residential } \\
\text { area }\end{array}$ \\
\hline 1 & Songliang Road & 1026 & 26 & 26 & 0 & 0 & 1 & 1 & 0 \\
\hline 2 & Guangqu Road & 3264 & 54 & 19 & 1 & 1 & 1 & 1 & 1 \\
\hline 4 & Chao'fu Avenue & 3331 & 56 & 13 & 1 & 0 & 0 & 0 & 0 \\
\hline 5 & Tongchao Street & 1874 & 47 & 30 & 0 & 1 & 1 & 1 & 0 \\
\hline 6 & Station Road & 1117 & 28 & 23 & 0 & 1 & 1 & 1 & 0 \\
\hline 7 & Xinhua North Street & 1025 & 34 & 17 & 1 & 1 & 0 & 1 & 0 \\
\hline 8 & Xinhua North Street & 4815 & 69 & 12 & 1 & 1 & 0 & 1 & 0 \\
\hline 9 & Dongdan North Street & 2507 & 42 & 14 & 1 & 1 & 0 & 1 & 0 \\
\hline 10 & Tonghu Street & 1206 & 30 & 24 & 0 & 1 & 0 & 1 & 1 \\
\hline
\end{tabular}
indicator is calculated, as shown in Table 2.

Table 1. Indicators of bus lane. 
The comprehensive importance degree of each dedicated lane is calculated according to the model of the comprehensive importance degree, with relevant information is shown in Table 3.

According to Table 3, based on the analysis of allocation difficulties, since there is no station on the main road of the Fourth Ring Road at present, it is necessary to take corresponding engineering measures to increase stations or overpasses, and allocate Bus Lane by coordinating with the optimization of public transit network, so the Fourth Ring Road will not be considered temporarily. Chao'fu Avenue, Xidan North Street and Dongdan North Street will not be considered temporarily due to limitations of road conditions. Accordingly, the allocation plans for Bus Lane in 2017 are formulated according to the comprehensive importance. There are a total of 6 Bus Lane, with a length of 49.4 kilometers. The detailed information is shown in Table 4.

Figure 3 Status Quo of Bus Lane and Allocation Plans in 2017.

Table 2. Indicator weight.

\begin{tabular}{|c|c|c|c|c|}
\hline $\begin{array}{l}\text { Government } \\
\text { departments }\end{array}$ & $\begin{array}{l}\text { Colleges and } \\
\text { universities }\end{array}$ & $\begin{array}{l}\text { Scientific research } \\
\text { institutions }\end{array}$ & Indicator & $\begin{array}{l}\text { Final weight } \\
\text { after weighting }\end{array}$ \\
\hline 0.6 & 0.2 & 0.3 & & \\
\hline 0.243672 & 0.310622 & 0.246579 & $\begin{array}{l}\text { Passenger flow } \\
\text { of the section }\end{array}$ & 0.2823013 \\
\hline 0.242278 & 0.202427 & 0.232873 & Traffic flow & 0.179336236 \\
\hline 0.361661 & 0.269402 & 0.410466 & Speed & 0.237743191 \\
\hline 0.183403 & 0.217879 & 0.204746 & $\begin{array}{l}\text { Whether traffic jam } \\
\text { occurs frequently }\end{array}$ & 0.209068022 \\
\hline 0.118986 & 0.13967 & 0.105336 & Rapid commuting or not & 0.073820674 \\
\hline 0.038012 & 0.021234 & 0.023987 & $\begin{array}{l}\text { Whether it is a road } \\
\text { with key planning }\end{array}$ & 0.010015343 \\
\hline 0.045893 & 0.038759 & 0.028787 & Serving the functional area & 0.003258007 \\
\hline \multirow[t]{2}{*}{0.046978} & 0.035976 & 0.028974 & Serving the residential area & 0.00438443 \\
\hline & & Total & & 1.00 \\
\hline
\end{tabular}

Table 3. Comprehensive importance degree.

\begin{tabular}{cccc}
\hline S/N & Road name & Comprehensive importance degree & Mileage $(\mathrm{km})$ \\
\hline 1 & Songliang Road & 0.671560 & 8 \\
2 & Guangqu Road & 0.708029 & 23 \\
3 & The Fourth Ring Road & 0.567060 & 120 \\
4 & Chao'fu Avenue & 0.567062 & 7.6 \\
5 & Tongchao Street & 0.708020 & 5.4 \\
6 & Station Road & 0.671561 & 0.4 \\
7 & Xinhua North Street & 0.671560 & 3.2 \\
8 & Xinhua North Street & 0.671562 & 11 \\
9 & Dongdan North Street & 0.671563 & 9 \\
10 & Tonghu Street & 0.671561 & 9.4 \\
\hline
\end{tabular}




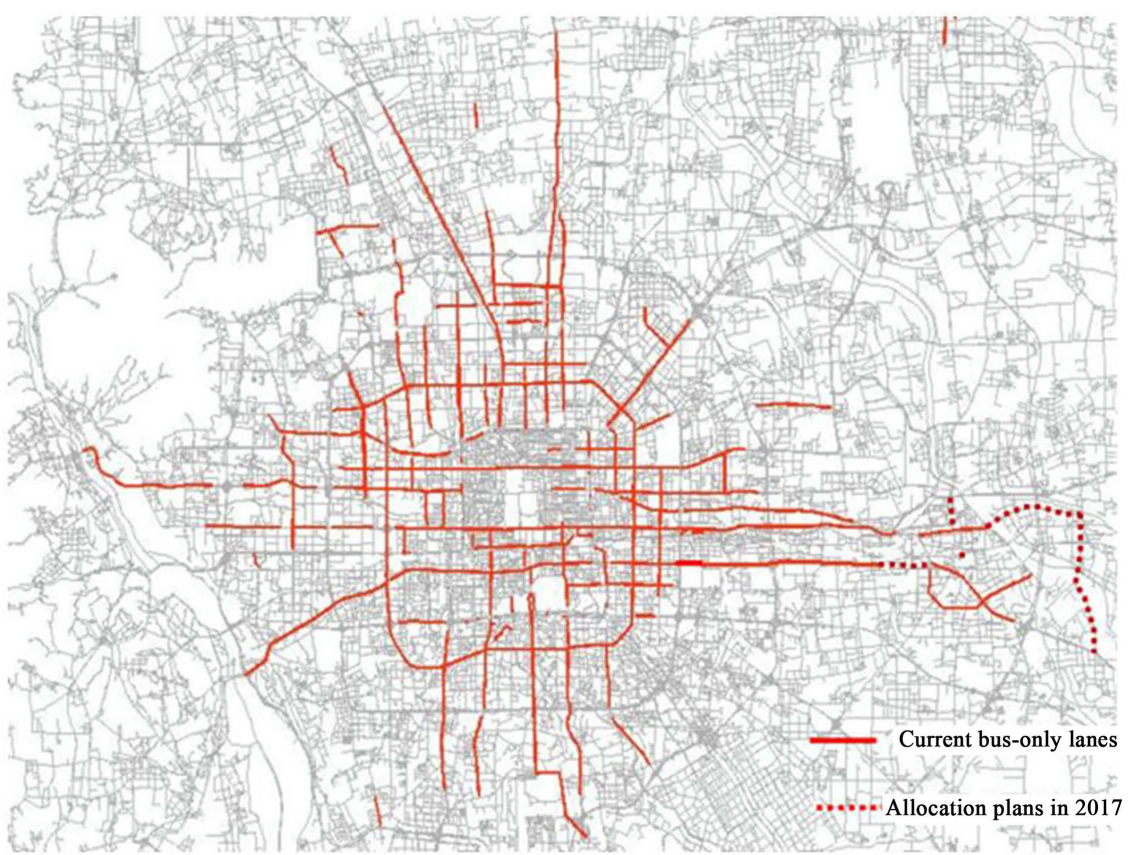

Figure 3. Status quo of bus lane and allocation plans in 2017.

Table 4. Allocation plans for bus lane in 2017.

\begin{tabular}{cccc}
\hline S/N & Road name & Comprehensive importance degree & Mileage $(\mathrm{km})$ \\
\hline 1 & Songliang Road & 0.671560 & 8 \\
2 & Guangqu Road & 0.708029 & 23 \\
3 & Tongchao Street & 0.708020 & 5.4 \\
4 & Station Road & 0.671561 & 0.4 \\
5 & Xinhua North Street & 0.671560 & 3.2 \\
6 & Tonghu Street & 0.671561 & 9.4 \\
& & & 49.4
\end{tabular}

Compared with the actual Bus Lane allocated in 2017, allocation of Bus Lane on Tongchao Street has not been implemented yet due to road construction, and other calculation results are all allocated as planned. The conformity between the allocation plan and the actual implementation reaches $90 \%$. It can be seen that the method used in this study is feasible.

\section{Conclusion}

This paper, by analyzing the status quo of allocation of Bus Lane in Beijing, has proposed the indicator system and factors influencing the time sequence of construction of Bus Lane, and built a theoretical model for time sequence of construction of the Bus Lane, providing scientific method systems and procedures for assistance of the decision-making of construction of the Bus Lane. Through the analysis of the allocation of Bus Lane in 2017, the conformity between the allocation plans and the actual implementation is up to $90 \%$. The theoretical 
method provided in this study is feasible and supports the allocation of Bus Lane in Beijing in a reasonable and effective manner.

\section{Conflicts of Interest}

The authors declare no conflicts of interest regarding the publication of this paper.

\section{References}

[1] Ministry of Transport (2013) Notice on Printing and Distributing the Indicator System for Examination and Evaluation of Transit Metropolis. The Ministry of Transport, Beijing.

[2] Beijing, DB11/T1163-2015, Specifications for Setting of Bus Lane, Beijing, 2015.

[3] Bai, Y., Xue, K. and Yang, X.G. (2004) Discussion on Benefit Evaluation Methods of Bus Lane. Journal of Highway and Transportation Research and Development, 21, 102-105.

[4] Lin, X.H. (2013) Benefit Evaluation and Simulation of Bus Lane-Tianyuan Road of Guangzhou Is Taken for Example. Technology \& Economy in Areas of Communications, 15, 32-35.

[5] Yang, J. and Chen, H. (2015) Indicators and Methods for Evaluation of Comprehensive Operating Efficiency of Bus Lane. Journal of Chang an University (Natural Science Edition), 35, 230-234. 